\title{
Fabrication and Characterization of Phthalocyanine-Based Organic Solar Cells
}

\author{
Makoto Iwase, Atsushi Suzuki*, Tsuyoshi Akiyama, Takeo Oku* \\ Department of Materials Science, The University of Shiga Prefecture, Shiga, Japan \\ Email: ${ }^{*}$ oku@mat.usp.ac.jp, ${ }^{*}$ suzuki@mat.usp.ac.jp
}

Received 6 February 2014; revised 9 March 2014; accepted 21 March 2014

Copyright (C) 2014 by authors and Scientific Research Publishing Inc.

This work is licensed under the Creative Commons Attribution International License (CC BY). http://creativecommons.org/licenses/by/4.0/

(c) (i) Open Access

\begin{abstract}
Organic solar cells using poly (copper phthalocyanine), copper tetrakis (4-cumylphenoxy) phthalocyanine, copper phthalocyanine and titanyl phthalocyanine were fabricated and characterized. Photovoltaic properties of the solar cells with inverted structures were investigated by optical absorption, current density-voltage characteristic and incident photon to current conversion efficiency. These phthalocyanines absorbed light with wavelength longer than $500 \mathrm{~nm}$. A carrier transport mechanism is proposed based on the energy level diagram.
\end{abstract}

\section{Keywords}

Organic Solar Cells, Phthalocyanine, Copper, Poly Phthalocyanine

\section{Introduction}

Organic solar cells based on organic semiconductors have been widely studied due to their low cost and easy fabrication process. Phthalocyanines have a great advantage for carrier mobility and photo-properties by changing modification of molecular structures with various central metal and chemical substitution. Recently, phthalocyanine/fullerene solar cells have been investigated, and the conversion efficiency of 2\% was obtained [1] [2]. Phthalocyanines have a photovoltaic property, heat-resistance, light-stability, and high optical absorption in the visible range, and are applied for semiconducting devices, catalyst for fuel cells and solar cells [3]-[6]. Many studies on the modified phthalocyanine with various central metal atoms and chemical substitutions have been reported to optimize electronic structures for improving photovoltaic performance, such as open circuit voltage and conversion efficiency [7]-[10]. For example, the poly (copper phthalocyanine) (PolyCuPc) has high conductivity [11] [12]. The titanyl phthalocyanine (TiOPc) shows phase transition from H-aggregate (phase I) to J-aggregate (phase II) that absorbs at longer wavelengths by exposure vapor toluene to TiOPc over a $1 \mathrm{~h}$ period,

\footnotetext{
*Corresponding author.
}

How to cite this paper: Iwase, M., Suzuki, A., Akiyama, T. and Oku, T. (2014) Fabrication and Characterization of Phthalocyanine-Based Organic Solar Cells. Materials Sciences and Applications, 5, 278-284. 
which is a practical method to convert Phase I to Phase II [13]-[16].

In spite of easy fabrication, organic solar cells are reported to be unstable because of photo-induced diffusion of $\mathrm{O}_{2}$ into $\mathrm{C}_{60}$, or the reaction of $\mathrm{Al}$ electrodes with oxygen and water [17]. Solar cells incorporating non-corrosive Au electrodes have been recently developed to overcome the instability. Such solar cells have an inverted device structure compared with the normal structure, in which photo-generated electrons flow through an external circuit from the transparent working electrode to Au electrode [18].

The purpose of the present work is to fabricate organic photovoltaic cells with PolyCuPc, copper tetrakis (4cumylphenoxy) phthalocyanine (Tc-CuPc), copper phthalocyanine (CuPc) and TiOPc as donor materials and [6,6]-phenyl- $\mathrm{C}_{61}$-butyric acid methyl ester (PCBM) as an accepter material [19] [20]. Light-induced charge separation was investigated, and a mechanism of the photovoltaic properties was discussed on the basis of experimental results. The present work will suggest a guideline for optimizing the photovoltaic properties of inverted organic solar cells using PCBM/phthalocyanine.

\section{Experimental Procedures}

Inverted bulk-heterojunction organic solar cells were fabricated as a following process. Indium tin oxide (ITO) substrates (Xin Yan Technology, $\sim 10 \Omega / \square$ ) were cleaned by an ultrasonic bath with acetone and methanol, and were dried by nitrogen gas. The $\mathrm{TiO}_{\mathrm{x}}$ precursor solution was prepared by adding titanium isopropoxide (TTIP, $0.46 \mathrm{ml})$ to 2-methoxyethanol $(2.5 \mathrm{ml})$ and acetylacetone $(0.61 \mathrm{ml})$. The $\mathrm{TiO}_{\mathrm{x}}$ precursor solution was spin-coated on ITO glass plates and annealed at $150^{\circ} \mathrm{C}$ for $60 \mathrm{~min}$. The active layer was fabricated with a mixture of PolyCuPc (Sigma Aldrich Corp.) or Tc-CuPc (Sigma Aldrich Corp) and PCBM (American Dye Source, Inc) at weight ratio of 1:2 in $1 \mathrm{~mL}$ o-dichlorobenzene on a $\mathrm{TiO}_{\mathrm{x}}$ layer by spin-coating method, and annealed at $140^{\circ} \mathrm{C}$ for $20 \mathrm{~min}$. A thin layer of poly(3,4-ethylenedioxy-thiophene):poly(4-styrene sulfonic acid) (PEDOT:PSS) was spin-coated on the active layer. Gold $\mathrm{(Au}$ ) was evaporated thermally as a top electrode under vacuum condition, resulting in cells with an active area of $16 \mathrm{~mm}^{2}$.

$\mathrm{CuPc}$ and TiOPc-based solar cells were fabricated as a following process. PCBM as an acceptor material was spin-coated on $\mathrm{TiO}_{\mathrm{x}}$ layer, and phthalocyanines as a donor material were evaporated in vacuum on the acceptor layers. A TiOPc (Sigma Aldrich Corp.) film was spin coated by toluene, which changed Phase I to Phase II [13]. A thin layer of PEDOT:PSS was spin-coated on the active layer. Au was evaporated as a top electrode in a vacuum. Structure models of the starting materials are shown in Figure 1(a). Schematic structures of the inverted organic solar cells are shown in Figure 1(b) and Figure 1(c). The current density-voltage (J-V) characteristics of the photovoltaic solar cells were measured both in the dark and under illumination at $100 \mathrm{~mW} \cdot \mathrm{cm}^{-2}$ by using AM 1.5 solar simulator (San-ei Electric, XES-301S) and potentiostat (Hokuto Denko Co., HSV-110).

The photovoltaic power conversion efficiency of solar cell is determined by following formula.

$$
\begin{gathered}
\eta=\frac{\mathrm{V}_{\mathrm{oc}} \times \mathrm{J}_{\mathrm{sc}} \times \mathrm{FF}}{100\left[\mathrm{mWcm}^{-2}\right]} \times 100=\mathrm{V}_{\mathrm{oc}} \times \mathrm{J}_{\mathrm{sc}} \times \mathrm{FF} \\
\mathrm{FF}=\frac{\mathrm{V}_{\text {max }} \times \mathrm{J}_{\max }}{\mathrm{V}_{\mathrm{oc}} \times \mathrm{J}_{\mathrm{sc}}}
\end{gathered}
$$

$\mathrm{V}_{\mathrm{oc}}$ is the open circuit voltage, $\mathrm{J}_{\mathrm{sc}}$ is the short circuit current density and FF is the fill factor. Light intensity is standardized at $100 \mathrm{~mW} / \mathrm{cm}^{2}$ of AM 1.5 spectrum. $V_{\max }$ and $J_{\max }$ are the voltage and current at the maximum power point.

Optical absorption was investigated by means of ultraviolet-visible-near-infrared spectroscopy (Jasco V-670). The incident photon-to-current efficiencies (IPCE) of the solar cells were obtained from the short-circuit photocurrents under irradiation of monochromatic light.

\section{Results and Discussion}

Figure 2 shows X-ray diffraction patterns of TiOPc Phase I and TiOPc Phase II films. No diffraction peak of TiOPc Phase I at $26.3^{\circ}$ was observed.

On the other hand, after the spin coated by toluene, a 010 diffraction peak at $2 \theta=7.58^{\circ}(1.17 \mathrm{~nm})$ due to Phase II is observed, and the crystallite size was calculated to be $34 \mathrm{~nm}$ by using using Scherrer's formula. 


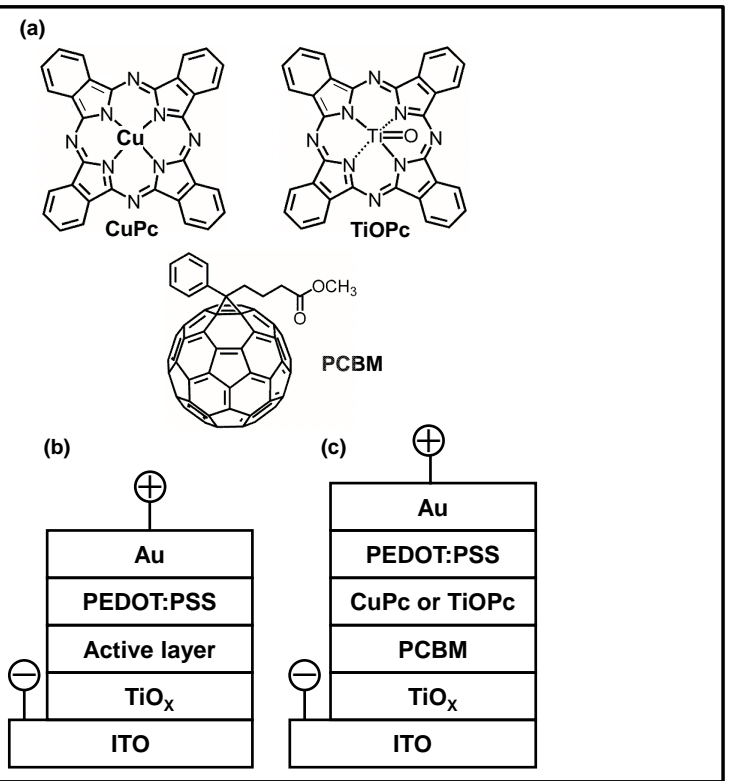

Figure 1. Structures of (a) starting materials, (b) bulk-heterojunction and (c) heterojunction solar cells.

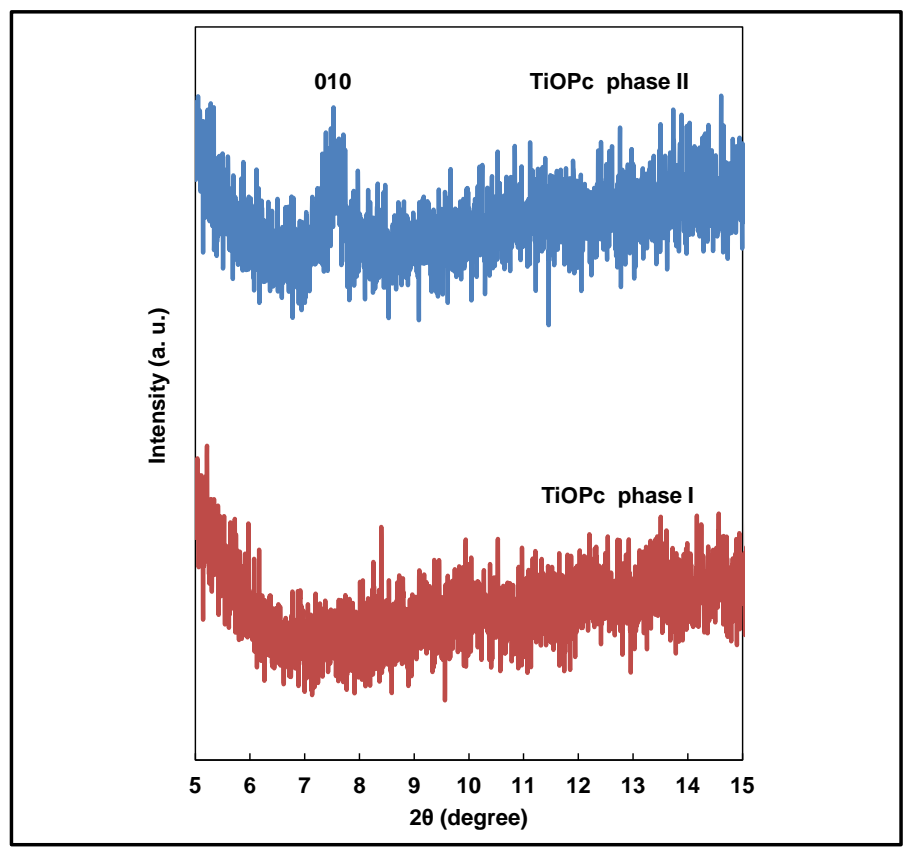

Figure 2. X-ray diffraction patterns of TiOPc Phase I and TiOPc Phase II films.

Therefore, TiOPc was transformed from Phase I to Phase II by toluene. The schematic illustrations of Phase I and Phase II structures are shown in Figure 3.

Figure 4 shows absorption spectra of PolyCuPc, Tc-CuPc, CuPc, TiOPc Phase I and TiOPc Phase II thin films. The measurement region is in the range of $300-1000 \mathrm{~nm}$. The optical absorptions at 370, 400, 340, 350 and 360 nm correspond to those of Soret band of PolyCuPc, Tc-CuPc, CuPc, TiOPc Phase I and TiOPc Phase II, respectively.

Figure 5 shows measured J-V characteristic curves of PCBM:PolyCuPc, PCBM:Tc-CuPc, PCBM/CuPc, PCBM/TiOPc Phase I and PCBM/TiOPc Phase II solar cells. Measured parameters of the solar cells under illu- 


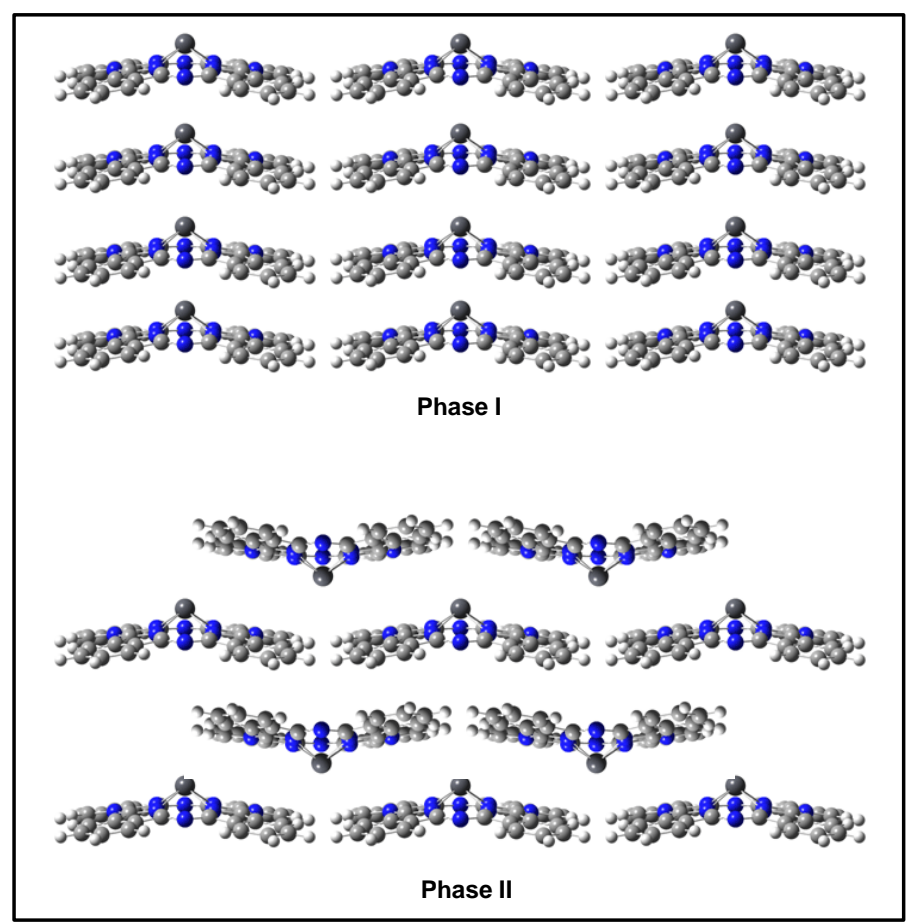

Figure 3. Schematic illustrations of Phase I and Phase II.

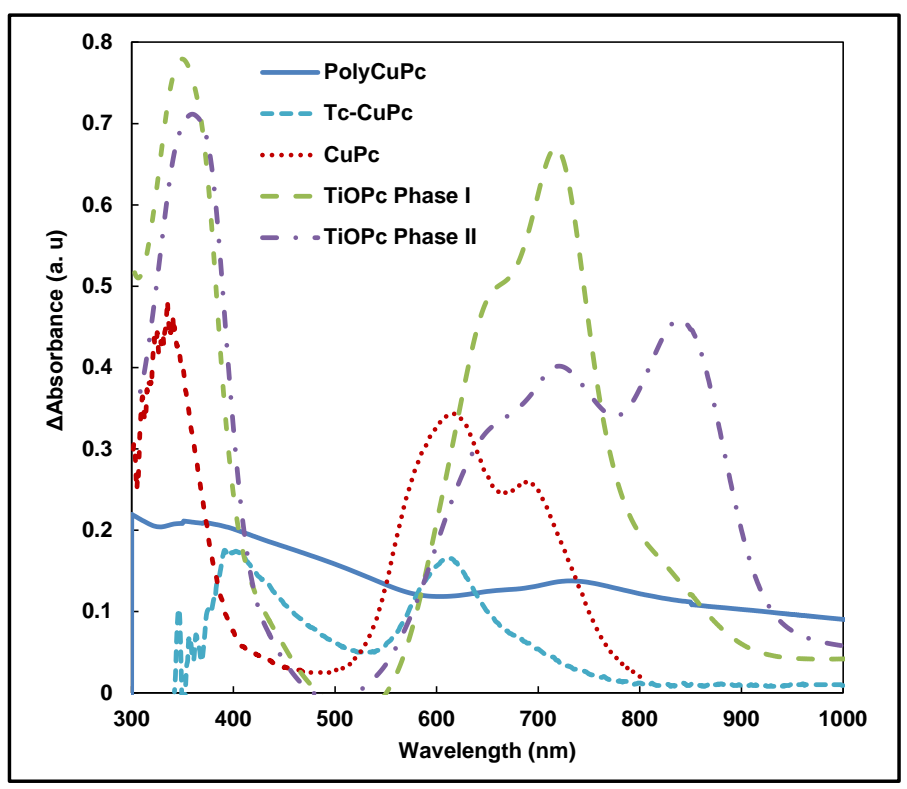

Figure 4. Absorption spectra of phthalocyanine thin films.

mination are summarized in Table 1. A solar cell with a PCBM:PolyCuPc structure showed the highest power conversion efficiency $(\eta)$. The PCBM:PolyCuPc solar cell provided $\eta$ of $2.6 \times 10^{-2} \%$, fill factor (FF) of 0.32 , and short-circuit current density $\left(\mathrm{J}_{\mathrm{SC}}\right)$ of $0.23 \mathrm{~mA} \cdot \mathrm{cm}^{-2}$ and open-circuit voltage $\left(\mathrm{V}_{\mathrm{OC}}\right)$ of $0.35 \mathrm{~V}$.

IPCE spectra of solar cells are shown in Figure 6. IPCE peaks at 350 and 550 - $950 \mathrm{~nm}$ correspond to the PCBM and phthalocyanines, respectively. However, no special IPCE peak was observed from PolyCuPc, as shown in Figure 6.

On the other hand, a strong IPCE peak at $350 \mathrm{~nm}$ was observed for the PCBM/PolyCuPc solar cell, which would be due to the PCBM. It is thought that PolyCuPc with high conductivity did not work as p-type semicon- 
Table 1. Measured parameters of the present solar cells.

\begin{tabular}{ccccc}
\hline Device Structure & $\mathrm{J}_{\mathrm{SC}}\left(\mathrm{mA} \cdot \mathrm{cm}^{-2}\right)$ & $\mathrm{V}_{\mathrm{OC}}(\mathrm{V})$ & $\mathrm{FF}$ & $\eta(\%)$ \\
\hline PCBM:PolyCuPc & 0.23 & 0.35 & 0.32 & 0.026 \\
PCBM:Tc-CuPc & 0.033 & 0.20 & 0.32 & 0.0022 \\
PCBM/CuPc & 0.027 & 0.29 & 0.23 & 0.018 \\
PCBM/TiOPc Phase I & 0.068 & 0.50 & 0.33 & 0.011 \\
PCBM/TiOPc Phase II & 0.076 & 0.31 & 0.42 & 0.010 \\
\hline
\end{tabular}

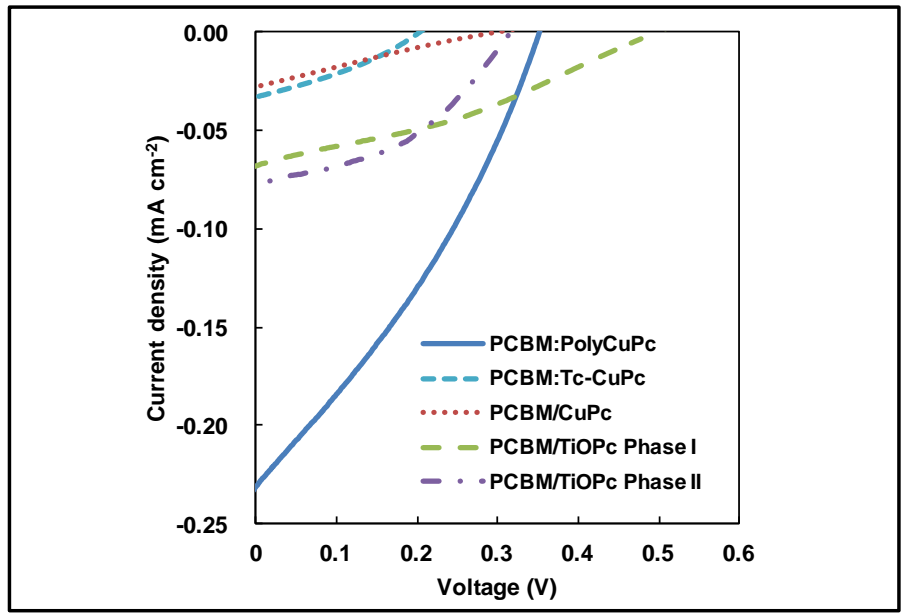

Figure 5. J-V characteristics of the present solar cells.

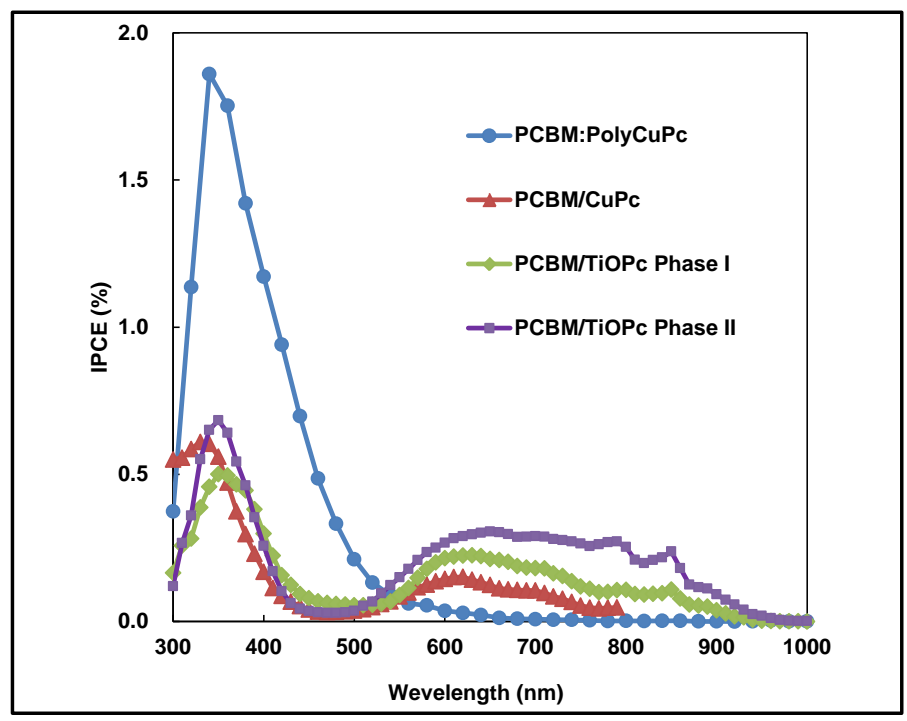

Figure 6. IPCE spectra of the present solar cells.

ductor but worked as carrier transport of PCBM. An IPCE peak of TiOPc was enhanced by phase changing from I to II. Therefore, the $\mathrm{J}_{\mathrm{SC}}$ of PCBM/TiOPc Phase II was higher than that of PCBM/TiOPc Phase I.

An energy level diagram of the present solar cells is summarized as Figure 7. Previously reported values were used for the energy levels of the figures by adjusting to the present work [21]-[23]. In the cell with the inverted structure, electrons are transported to the ITO substrate, and holes are transported to the Au electrode. $\mathrm{V}_{\text {OC }}$ of organic solar cells is related with energy gap between highest occupied molecular orbital (HOMO) of phthalo- 


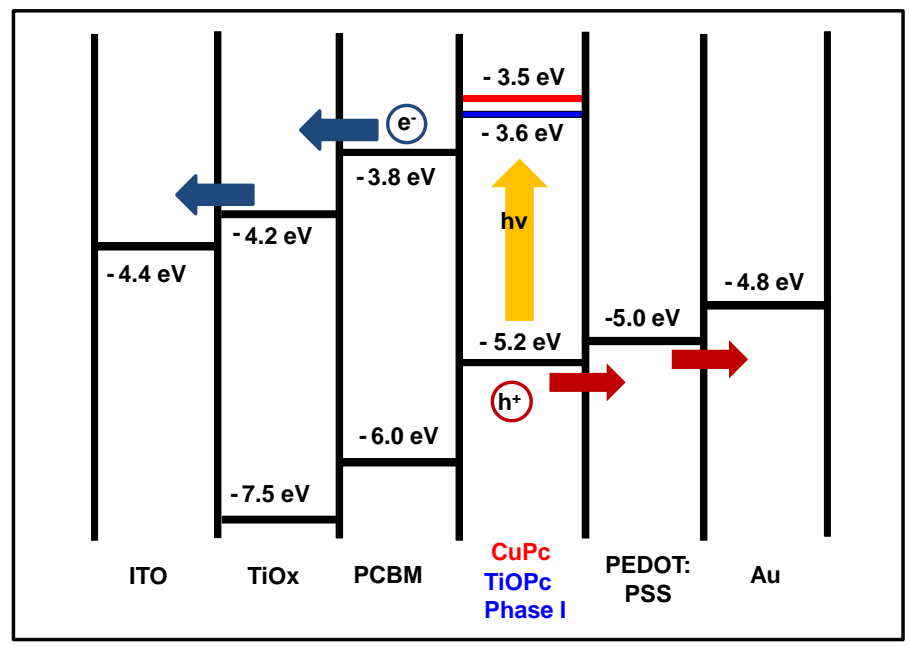

Figure 7. Energy level diagram of the present solar cells.

cyanine and lowest unoccupied molecular orbital (LUMO) of PCBM, and control of the energy levels is important to improve the photovoltaic performance. Control of HOMO and LUMO is possible by exchange of a central metal and introduction of a substituent group.

Most of heterojunction organic solar cells using phthalocyanines and $\mathrm{C}_{60}$ were fabricated by a vacuum deposition method. In the present work, soluble phthalocyanine and PCBM were spin-coated by the solution process. The present method without vacuum condition is low cost and easy fabrication process. PolyCuPc was reported to provide high electronic conductivity [12], and no data was reported on solar cells. The efficiency of PolyCuPc was higher than that of monomer CuPc and Tc-CuPc, and the PolyCuPc would be suitable for solar cells device application. The TiOPc Phase II with the shuttle cock-type structure also provided higher IPCE and FF as compared with Phase I, which would be suitable for the solar cell application [23].

\section{Conclusion}

Organic solar cells using PolyCuPc, Tc-CuPc, CuPc or TiOPc were fabricated and characterized. These phthalocyanines absorbed light with wavelength longer than $500 \mathrm{~nm}$, and the transition of TiOPc from Phase I to Phase II accelerated by exposure to toluene extended the absorption wavelength up to $950 \mathrm{~nm}$. A device with an inverted structure using PCBM:PolyCuPc provided $\mathrm{V}_{\mathrm{OC}}$ of $0.35 \mathrm{~V}, \mathrm{~J}_{\mathrm{SC}}$ of $0.23 \mathrm{~mA} \cdot \mathrm{cm}^{-2}$, FF of 0.32 , and $\eta$ of $0.026 \%$. A carrier transport mechanism is proposed based on the energy level diagram.

\section{References}

[1] Hori, T., Miyake, Y., Yamasaki, N., Yoshida, H., Fujii, A., Shimizu, Y. and Ozaki, M. (2010) Solution Processable Organic Solar Cell Based on Bulk Heterojunction Utilizing Phthalocyanine Derivative. Applied Physics Express, 3, 101602-1-3. http://dx.doi.org/10.1143/APEX.3.101602

[2] Hori, T., Fukuoka, N., Masuda, T., Miyake, Y., Yoshida, H., Fujii, A., Shimizuand, Y. and Ozaki, M. (2011) Bulk Heterojunction Organic Solar Cells Utilizing 1,4,8,11,15,18,22,25-Octahexylphthalocyanine. Solar Energy Materials \& Solar Cells, 95, 3087-3092. http://dx.doi.org/10.1016/j.solmat.2011.06.039

[3] Bamsey, N.M., Yuen, A.P., Hor, A.M., Klenkler, R., Preston J.S. and Loutfy, R.O. (2011) Integration of an M-phthalocyanine Layer into Solution-Processed Organic Photovoltaic Cells for Improved Spectral Coverage. Solar Energy Materials \& Solar Cells, 95, 1970-1973. http://dx.doi.org/10.1016/j.solmat.2011.01.042

[4] Varotto, A., Nam, C.Y., Radivojevic, I., Tome, J.P.C., Cavaleiro, J.A.S., Black C.T. and Drain, C.M. (2010) Phthalocyanine Blends Improve Bulk Heterojunction Solar Cells. Journal of the American Chemical Society, 132, $2552-2554$. http://dx.doi.org/10.1021/ja907851x

[5] Takeda, A., Oku, T., Suzuki, A., Akiyama, T. and Yamasaki, Y. (2013) Fabrication and Characterization of Fullerenebased Solar Cells Containing Phthalocyanine and Naphthalocyanine Dimers.Synthetic Metals, 177, 48-51. http://dx.doi.org/10.1016/j.synthmet.2013.06.011

[6] Oku, T., Takeda, A., Nagata, A., Kidowaki, H., Kumada, K., Fujimoto, K., Suzuki, A., Akiyama, T., Yamasaki, Y. and 
Ōsawa, E. (2013) Microstructures and Photovoltaic Properties of $\mathrm{C}_{60}$-based Solar Cells with Copper Oxides, CuInS ${ }_{2}$, Phthalocyanines, Porphyrin, PVK, Nanodiamond, Germanium and Exciton-diffusion Blocking Layers. Materials Technology, 28, 21-39. http://dx.doi.org/10.1179/1753555712Y.0000000042

[7] Bechara, R., Petersen, J., Gernigon, V., Leveque, P., Heiser, T., Toniazzo, V., Ruchand, D. and Michel, M. (2012) PEDOT:PSS-Free Organic Solar Cells Using TetrasulfonicCopper Phthalocyanine as Buffer Layer. Solar Energy Materials \& Solar Cells, 98, 482-485. http://dx.doi.org/10.1016/j.solmat.2011.11.005

[8] Thuy, T., Luong, T., Chen, Z. and Zhu, H. (2010) Flexible Solar Cells based on Copper Phthalocyanine and BuckminsterFullerene. Solar Energy Materials \& Solar Cells, 94, 1059-1063. http://dx.doi.org/10.1016/j.solmat.2010.02.023

[9] Huang, C.J., Ke, J.C., Chen, W.R., Meenand, T.H. and Yang, C.F. (2011) Improved the Efficiency of Small Molecule Organic Solar Cell by Double Anode Buffer Layers. Solar Energy Materials \& Solar Cells, 95, 3460-3464. http://dx.doi.org/10.1016/j.solmat.2011.08.006

[10] Cheng, F., Fang, G., Fan, X., Liu, N., Sun, N., Qin, P., Zheng, Q., Wan, J. and Zhao, X. (2011) Enhancing the ShortCircuit Current and Efficiency of Organic Solar Cells Using $\mathrm{MoO}_{3}$ and CuPc as Buffer Layers. Solar Energy Materials \& Solar Cells, 95, 2914-2919. http://dx.doi.org/10.1016/j.solmat.2011.06.027

[11] Snow, A.W., Griffith, J.R. and Marullo, N.P. (1984) Syntheses and Characterization of Heteroatom-Bridged MetalFree Phthalocyanine Network Polymers and Model Compounds. Macromolecules, 17, 1614-1624. http://dx.doi.org/10.1021/ma00138a033

[12] Romero, P.G., Lee, Y.S. and Kertesz, M. (1988) Band Structure Calculation of Extended Poly(Copper Phthalocyanine) One-Dimensional and Two-Dimensional Polymers. Inorganic Chemistry, 27, 3672-3675. http://dx.doi.org/10.1021/ic00293a049

[13] Obata, N., Sato, Y., Nakamura, E. and Matsuo, Y. (2011) Small-Molecule-Based Organic Photovoltaic Devices Covering Visible and Near-Infrared Absorption through Phase Transition of Titanylphthalocyanine Induced by Solvent Exposure. Japanese Journal of Applied Physics, 50, 121603-121606. http://dx.doi.org/10.1143/JJAP.50.121603

[14] Placencia, D., Wang, W., Shallcross, R.C., Nebesny, K.W., Brumbach, M. and Armstrong, N.R. (2009) Organic Photovoltaic Cells Based On Solvent-Annealed, Textured Titanyl Phthalocyanine/C60 Heterojunctions. Advanced Functional Materials, 19, 1913-1921. http://dx.doi.org/10.1002/adfm.200801723

[15] Brumbach, M., Placencia, D. and Armstrong, N.R. (2008) Titanylphthalocyanine/C ${ }_{60}$ Heterojunctions: Band-Edge Offsets and Photovoltaic Device Performance. The Journal of Physical Chemistry C, 112, 3142-3151. http://dx.doi.org/10.1021/jp0772171

[16] Yamashita, A., Maruno, T. and Hayashi, T. (1994) Phase-Selective Formation of Titanylphthalocyanine Thin Films by Organic Molecular Beam Deposition. The Journal of Physical Chemistry, 98, 12695-12701. http://dx.doi.org/10.1021/j100099a037

[17] Yoshida, K., Oku, T., Suzuki, A., Akiyamaand, T. and Yamasaki, Y. (2012) Fabrication and Characterization of Phthalocyanine/ $\mathrm{C}_{60}$ Solar Cells with Inverted Structure. Advances in Chemical Engineering and Science, 2, 461-464. http://dx.doi.org/10.4236/aces.2012.24056

[18] Kuwabara, T., Nakayama, T., Uozumi, K., Yamaguchi, T. and Takahashi, K. (2008) Highly Durable Inverted-Type Organic Solar Cell Using Amorphous Titanium Oxide as Electron Collection Electrode Inserted between ITO and Organic Layer. Solar Energy Materials \& Solar Cells, 92, 1476-1482. http://dx.doi.org/10.1016/j.solmat.2008.06.012

[19] Kawashima, A., Oku, T., Suzuki, A., Kikuchi, K. and Kikuch, S. (2012) Microstructures and Photovoltaic Properties of Polysilane/ $\mathrm{C}_{60}$-Based Solar Cells. Materials Sciences and Applications, 43, 557-561. http://dx.doi.org/10.4236/msa.2012.38079

[20] Motoyoshi, R., Suzuki, A., Kikuchi, K. and Oku, T. (2009) Formation and Characterization of Copper Tetrakis (4-Cumylphenoxy) Phthalocyanine: Perylene Solar Cells. Synthetic Metals, 159, 1345-1348. http://dx.doi.org/10.1016/j.synthmet.2009.03.010

[21] Oku, T., Nose, S., Yoshida, K., Suzuki, A., Akiyama, T. and Yamasaki, Y. (2013) Fabrication and Characterization of Silicon Naphthalocyanine, Gallium phthalocyanine and Fullerene-Based Organic Solar Cells with Inverted Structures,. Journal of Physics: Conference Series, 433, 012025-1-7. http://dx.doi.org/10.1088/1742-6596/433/1/012025

[22] Yoshida, K., Oku, T., Suzuki, A., Akiyama, T. and Yamasaki, Y. (2013) Fabrication and Characterization of PCBM:P3HT Bulk Heterojunction Solar Cells Doped with Germanium Phthalocyanine or Germanium Naphthalocyanine. Materials Sciences and Applications, 4, 1-5. http://dx.doi.org/10.4236/msa.2013.44A001

[23] Hiramoto, M., Kitada, K., Iketaki, K. and Kaji, T. (2011) Near Infrared Light Driven Organic p-i-n Solar Cells Incorporating Phthalocyanine J-Aggregate. Applied Physics Letters, 98, 023302-023305. http://dx.doi.org/10.1063/1.3534804 